\title{
Single-Stage Operation for Traumatic Thoracolumbar Fractures with Severe Dislocation via a Posterior Approach Alone: A Case Series
}

\author{
Tek Başına Posterior Yaklaşımla Şiddetli Dislokasyonlu Travmatik \\ Torakolumber Kirılarda Tek Evreli Ameliyat: Vaka Serisi
}

\author{
Wei XIONG, Feng LI, Fan ZHANG, Xiwei HUO, Anming CHEN \\ Tongji Hospital, Tongji Medical College, Huazhong University of Science and Technology, Department of Orthopaedics, Wuban, P.R. China
}

Correspondence address: Feng LI / E-mail: lifengtongji@163.com

\begin{abstract}
AIM: This study reports a technique for treating severe thoracolumbar fractures with single-stage decompression, reduction, reconstruction, and stabilization via an entirely posterior approach.

MATERIAL and METHODS: The cases of 11 patients with severe traumatic thoracolumbar fractures/dislocations that were managed with single-stage decompression, reduction, reconstruction, and stabilization via an entirely posterior approach were included. Data on age, sex, mechanism of injury, associated trauma, neurological status, surgical technique, and clinical outcome were reviewed retrospectively.

RESULTS: Of the 11 patients, two presented with primarily coronal displacement and nine with sagittal displacement. Coronal displacement was corrected from $19 \%$ preoperatively to $4.0 \%$ at the last follow-up evaluation. Sagittal displacement was reduced from $73.0 \%$ preoperatively to $3.0 \%$ at the last follow-up evaluation. After a mean follow-up period of 20.7 (range 16-30) months, no patient complained of local pain and no significant loss of correction or hardware failure was observed.
\end{abstract}

CONCLUSION: Our experience proves that the single-stage posterior approach is safe and biomechanically reliable for treating severe thoracolumbar fractures/dislocations. Therefore, the presented technique is an alternative approach for this rare injury.

KEYWORDS: Thoracolumbar fracture, Severe dislocation, Single-stage, Posterior approach

öz

AMAÇ: Bu çalışma, tamamen posterior bir yaklaşımla tek evreli dekompresyon, redüksiyon, rekonstrüksiyon ve stabilizasyon ile şiddetli torakolumber kırıkları tedavi etmek için bir tekniği bildirmektedir.

YÖNTEM ve GEREÇLER: Tamamen posterior yaklaşımla tek evreli dekompresyon, redüksiyon, rekonstrüksiyon ve stabilizasyonla tedavi edilen şiddetli travmatik torakolumber kırık/dislokasyonu olan 11 vaka dahil edilmiştir. Yaş, cinsiyet, yaralanma mekanizması, ilgili travma, nörolojik durum, cerrahi teknik ve klinik sonuçlarla ilgili veriler retrospektif olarak gözden geçirilmiştir.

BULGULAR: 11 hasta içinde ikisi primer koronal displasman ve dokuzu sajital displasmanla gelmiştir. Sajital displasman preoperatif olarak $\% 19$ 'dan son takip değerlendirmesinde \%4,0'a düzeltilmiştir. Sajital displasman preoperatif olarak \%73,0'dan son takip değerlendirmesinde \%3,0'a düzeltilmiştir. Ortalama 20,7 (aralık 16-30) aylık takip süresiyle hiçbir hasta yerel ağrıdan yakınmamış ve düzeltmede önemli bir kayıp veya donanımla ilgili başarısızlık gözlenmemiştir.

SONUÇ: Deneyimimiz tek evreli posterior yaklaşımın şiddetli torakolumber kırıklar/dislokasyonlar tedavisinde güvenli ve biyomekanik olarak uyumlu olduğunu göstermiştir. Bu nedenle sunulan teknik bu nadir yaralanma için alternatif bir yaklaşımdır.

ANAHTAR SÖZCÜKLER: Torakolumber kırık, Şiddetli dislokasyon, Tek evre, Posterior yaklaşım

\section{INTRODUCTION}

Thoracic and lumbar fractures are the most common spinal injuries, constituting more than $50 \%$ of all spinal trauma (27). Nevertheless, fractures/dislocations of the thoracic and lumbar spine are rare, accounting for less than $3 \%$ of all spinal injuries (6). Few cases have been reported $(32,39,42)$. Severe spinal fracture/dislocation is defined as fracture combined with greater than $50 \%$ displacement of one vertebra in the coronal or sagittal plane (25). This form of trauma is even rarer and involves extremely unstable, complex lesions with canal compromise and neurological deficits. Typically, such injuries result from high-energy trauma and are combined with craniocerebral and abdominal visceral injuries. The ideal surgical strategy for thoracolumbar spinal fractures remains controversial, although the surgical techniques and instruments have been refined. Reported surgical approaches for fracture/dislocation include anterior, posterior, and combined approaches (37). Recently, an exclusively posterior 
approach has gained recognition for reconstructing the anterior and middle columns in patients with spinal deformity, tumors, and trauma $(19,35,44)$.

This report presents our experience in the surgical treatment of 11 cases of severe traumatic thoracolumbar fracture/ dislocation in which the reduction, reconstruction, and stabilization were done in one stage via an entirely posterior approach. Other issues related to the management of this uncommon injury are discussed.

\section{MATERIAL and METHODS}

Between June 2006 and October 2009, 287 patients with thoracolumbar injuries were treated in our department. Of these, 11 patients with severe dislocation were included in this retrospective study (eight men, three women; average age 38.8 (range 21-55) years). The follow-up period averaged 20.7 (range 16-30) months.

Neurological deficits were assessed using the American Spinal Injury Association (ASIA) impairment scale. The details of changes in motor and sensory function were also recorded. Pain was evaluated on a visual analogue scale (VAS).

Anteroposterior and lateral x-rays were taken of all patients pre- and postoperatively and at the last follow-up evaluation. Three-dimensional (3D) computed tomography (CT) or magnetic resonance imaging (MRI) was performed preoperatively. The vertebral body transition percentage was measured as recommended by the Spine Trauma Study Group (STSG) (14). The local sagittal alignment was evaluated with the Cobb angle, also as recommended by the STSG (14), with a negative value indicating lordotic or posterior transition and a positive value indicating kyphotic or anterior transition. Reconstruction stability was defined by the absence of progressive kyphosis, loss of deformity correction, hardware failure, screw loosening, and local pain related to position changes.

\section{Surgical technique}

Each patient was positioned prone and a long midline incision was made to expose two levels above and below the fracture/ dislocation level. Pedicle screws were placed bilaterally at these four vertebrae. A laminectomy was performed carefully, centered at the affected level to expose the dura widely. With the dura in direct view, the facet joint was removed, revealing the nerve root and eliminating it as an obstacle to reduction. Two short rods were placed on one side of the spine and each was used to temporarily connect the spinal anchors separately at the two levels above and below the trauma. Using a rod holder to hold each rod, a distractor instrument straddling the rods and contacting the rod holder was applied to separate both rods longitudinally. At the same time, the protruded disc and bone fragments compressing the dura anteriorly were exposed and removed from the other side, to prevent them from exacerbating the neurological injury during further reduction manipulation. Then, the rod holders were used to correct the coronal or sagittal plane translation while distraction was applied continuously. A long rod was positioned on the opposite side to achieve adequate spinal alignment, and the two short rods were replaced with a single long rod. The anterior reconstruction method depended on whether the affected vertebral body was intact. If the end plate of the adjacent vertebra at the dislocation level was essentially intact, a cancellous bone graft or Harms cage filled with autograft was implanted for interbody fusion, similar to the transforaminal lumbar interbody fusion (TLIF) technique. Otherwise, a subtotal corpectomy of the fractured vertebral body was performed and the vertebral body was replaced with an appropriately sized Harms cage packed with corpectomy bone. Additional posterolateral fusion was performed with autogenous bone grafts if available. For sagittal dislocations producing a step between the proximal and distal vertebrae at the dislocation after longitudinal compression and screw fixation, in situ contouring was used to eliminate this step. Finally, two transverse connectors were located proximal and distal to the constructs separately.

\section{Statistical analysis}

The data were analyzed using the paired $t$-test and nonparametric Wilcoxon test with the SPSS software (ver. 15.0; SPSS Inc., Chicago, IL, USA). The significance level was set at $p$ $<0.05$ for all analyses.

\section{RESULTS}

The cohort comprised 11 cases of severe traumatic thoracolumbar fracture/dislocation. The causes of injury were falls (seven patients), vehicular accidents (two patients), an overbreak (one patient), and a crash (one patient). The patients were divided into two groups according to the distribution of fracture/dislocation levels. The thoracic/thoracolumbar group included seven cases (three T11/12, one T12/L1, one $\mathrm{T} 8 / 9$, and two $L 1 / 2$ ) and the lumbar group included four cases (three L3/4 and one L4/5). Based on the displacement type, two patients presented with primarily coronal displacement (51.2-52.7\%) and nine patients with primarily sagittal displacement (six anterior and three posterior; 14.1-100\%; Table I).

All patients underwent surgery as soon as their vital signs were stable. The mean interval between injury and operation was 3.8 (range 2-8) days. The average operating time was 280 (range 226-350) min, and the mean blood loss was 1863 (range 800-3600) $\mathrm{mL}$.

Neurological deficits were detected in all patients. No neurological deterioration was observed postoperatively. Eight patients showed no improvement in neurological function during follow-up, whereas three patients experienced minor improvement of less than one ASIA grade, which presented as relieved numbness and partial muscle strength improvement.

Two-plane displacement was found in five cases in the thoracic/thoracolumbar group and in only two cases in the lumbar group. In the respective groups, coronal displacement 
was corrected from $24.3 \%$ (range $0-52.70 \%$ ) and $9 \%$ (range $0-23.2 \%$ ) preoperatively to $5.6 \%$ (range $0-23.1 \%$ ) and $1.5 \%$ (range $0-5.8 \%$ ) postoperatively, and maintained at $5.6 \%$ (range $0-21.4 \%$ ) and $1.3 \%$ (range $0-5.1 \%$ ) at the last follow-up evaluation. Sagittal displacement was reduced from $73 \%$ (range $14.1-100 \%$ ) and $82.5 \%$ (range $53.1-100 \%$ ) preoperatively to $2.7 \%$ (range $0-18.7 \%$ ) and $3.9 \%$ (range $0-15.6 \%$ ) postoperatively and $2.4 \%$ (range $0-16.8 \%$ ) and 2.9 (range $0-11.6 \%$ ) at the last follow-up evaluation. The preoperative Cobb angle at the injured level was $25.9 \pm 13.7^{\circ}$ in the thoracic/thoracolumbar group; the kyphotic deformity was reduced to $5.6 \pm 9.6^{\circ}$ postoperatively and $6.5 \pm 10^{\circ}$ at the last follow-up evaluation. In the lumbar group, the lordotic angle at the injured level was restored from $-0.8 \pm 10.6^{\circ}$ to $-20.5 \pm 6.6^{\circ}$ postoperatively and $-18.9 \pm 5.1^{\circ}$ at the last followup evaluation. The pre- and postoperative values differed significantly $(p<0.05)$, whereas no significant difference was observed between the values postoperatively and at the last follow-up evaluation ( $p>0.05$; Table II).

Seven patients also suffered from associated injuries, including rib fracture, hemo-/pneumothorax, calcaneus fracture, femur fracture, and soft-tissue trauma. Chest drains for hemo-/pneumothorax were inserted in three patients and kept in place until the completion of spine stabilization. The other associated injuries were operated on after the spine surgery if necessary.

All 11 patients underwent single-stage operations via an entirely posterior approach. Ten patients underwent posterior lumbar decompression, restoration, stabilization, and interbody fusion and one patient underwent posterior lumbar decompression, restoration, and anterior reconstruction with a titanium cage after a subtotal corpectomy. Representative images are shown in Figures 1 A, B, C, 2 A,B,C,

In this series, nine patients had uneventful postoperative recoveries with no obvious complication. Two patients suffered from cerebrospinal fluid (CSF) leakage because of severe dural lacerations caused by their injuries. Both were cured with conservative treatment. The average preoperative VAS score was 8.1. No patient complained of local pain at the last follow-up evaluation. The reconstruction was stable in all patients. No implant-related complication requiring revision was observed at the last follow-up visit.

\section{DISCUSSION}

Annually, approximately 160,000 patients sustain spinal column injuries in the United States. The majority are thoracolumbar injuries, which result from traffic accidents, falls, and extreme sports activities (2). Less than $3 \%$ involve fracture/dislocation injuries (7) and fracture with severe dislocation is even rarer, with only a few reported cases, most of which are lumbosacral (L5/S1). Thoracolumbar involvement is extremely rare $(38,40,43)$.

Traumatic fracture/dislocation is a high-energy trauma, and $80 \%$ of patients with thoracic fractures/dislocations have complete paralysis (33). As thoracolumbar fracture/ dislocation is usually associated with chest and visceral injuries requiring surgical treatment, a delayed diagnosis should be avoided. The incidence of non-spinal injuries in poly-trauma patients is about 38\% (11). In our series, $54.5 \%$ $(n=6)$ of patients suffered from associated non-spinal trauma, making a thorough evaluation of these patients paramount.

A proper radiographic evaluation algorithm helps not only to prevent a delayed diagnosis, which is not uncommon in poly-trauma patients, but also to optimize the treatment strategy. We use CT as the screening tool of choice for polytrauma patients who require a scan of the entire spine to detect noncontiguous fractures $(11,12)$. This modality will also detect injuries of the chest, abdomen, pelvis, and spine in a single scan. 3D-CT with sagittal and coronal reconstruction can provide a detailed depiction of the fracture morphology, position of the displaced vertebra or fragments, degree of canal stenosis, and bone structures potentially interfering with reduction. MRI is helpful for ruling out chronic fractures, evaluating the degree and extent of spinal cord compression and contusion, and predicting the prognosis (40). The inferior vena cava and aorta both cling to the spine, and severe fracture/dislocation can damage these vital vessels. Aortic disruption has been reported after high-energy trauma (13). A thorough literature search found that vascular injury concomitant with thoracolumbar fracture/dislocation was rare $(8,20)$, and we have seen no such case. We perform ultrasound and dynamic plasma D-dimer testing in all cases to exclude vascular injury and preoperative deep venous thrombosis (DVT). A hypercoagulable state can develop within a few hours of spinal cord injury (29). Compared with angiography $(32,42)$, our modality is economical and practical for perioperative monitoring. D-dimer is useful for detecting aortic dissection, aortic aneurysms, and DVT $(34,9,16)$. Since all of our patients had paraplegia and indirect interference with the great vessels during reduction manipulation, postoperative pharmacologic thromboprophylaxis was prescribed for 3 months (28).

According to the Thoracolumbar Injury Classification and Severity Score (TLICS) (36), the destruction of the posterior ligament complex and vertebral slippage make traumatic fracture/dislocation the most unstable spinal injury, almost inevitably associated with paraplegia and requiring operative treatment. No consensus has been reached on the optimal timing of spinal stabilization. We prefer early definitive surgery, as the patients were stable, as indicated by their normal hemodynamics, body temperature, coagulation system, and lung function. In a prospective study of poly-trauma patients with spinal fractures, McLain et al. (24) found that urgent $(<24$ $\mathrm{h}$ after injury) spinal stabilization was as safe as early surgical treatment (24-72 h after injury). Chipman et al. (5) reported that surgical treatment of thoracolumbar fractures within $72 \mathrm{~h}$ of injury in severely injured patients (TLICS $\geq 15$ ) was beneficial, with fewer complications, shorter hospital and intensive care unit stays, and no risk of increasing neurologic deficit. In our series, six patients underwent surgical treatment within $72 \mathrm{~h}$ of injury; five cases were delayed because these 


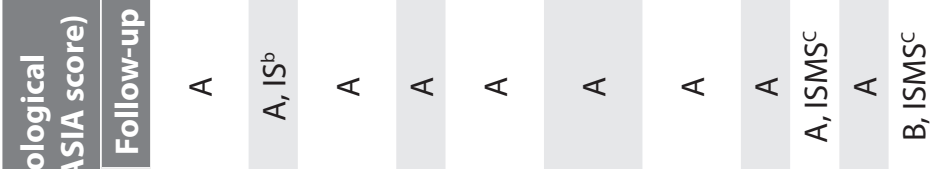 $\ll<\ll<\ll<\ll<$

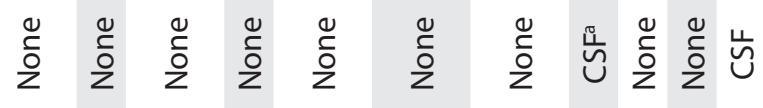

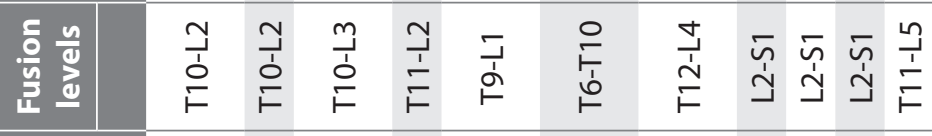 :}

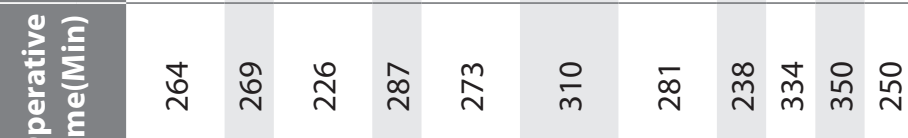

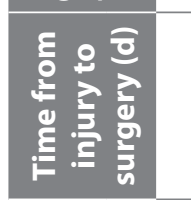

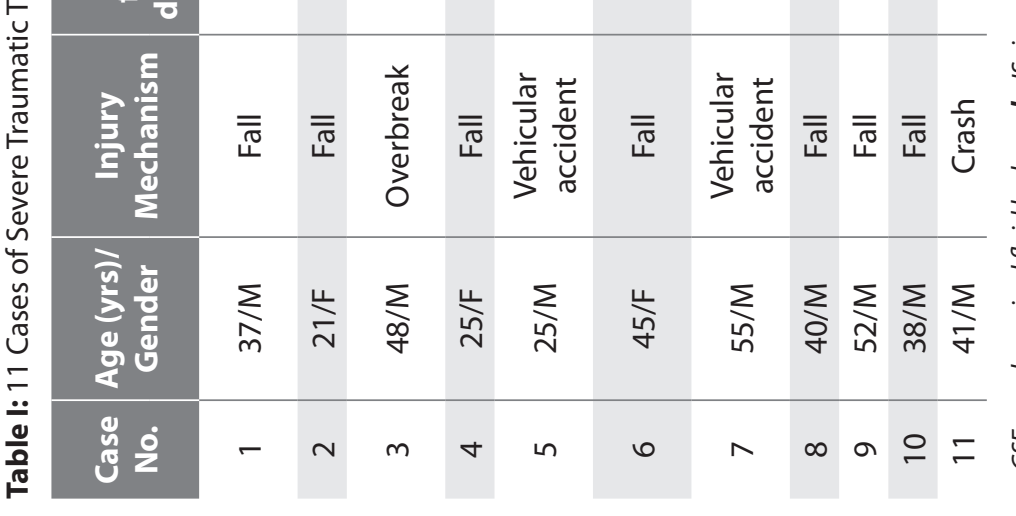

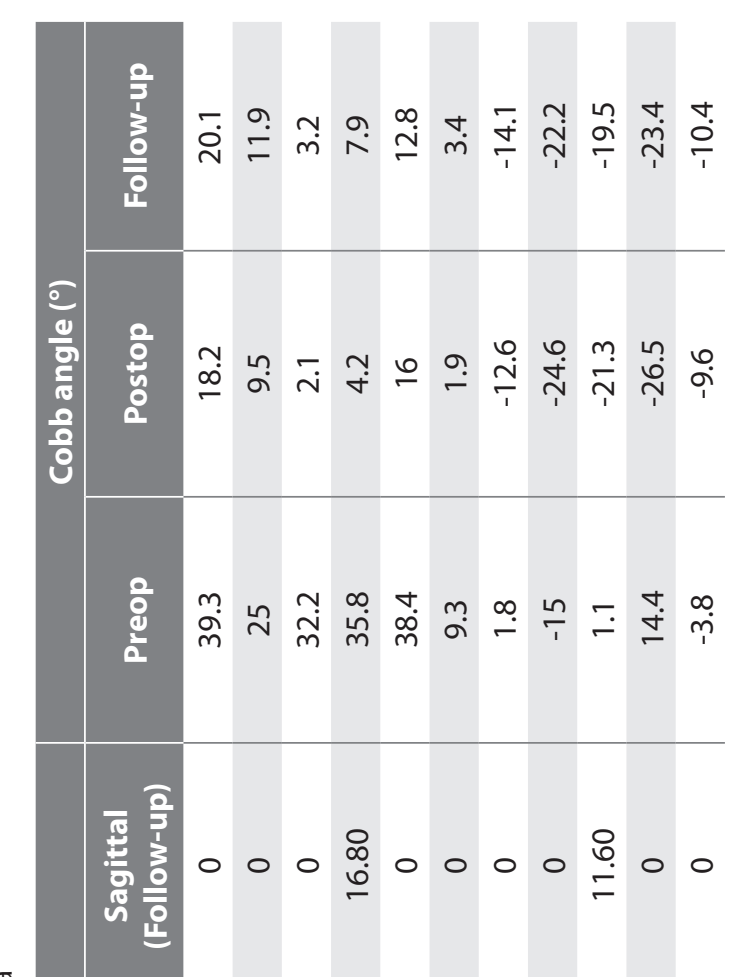

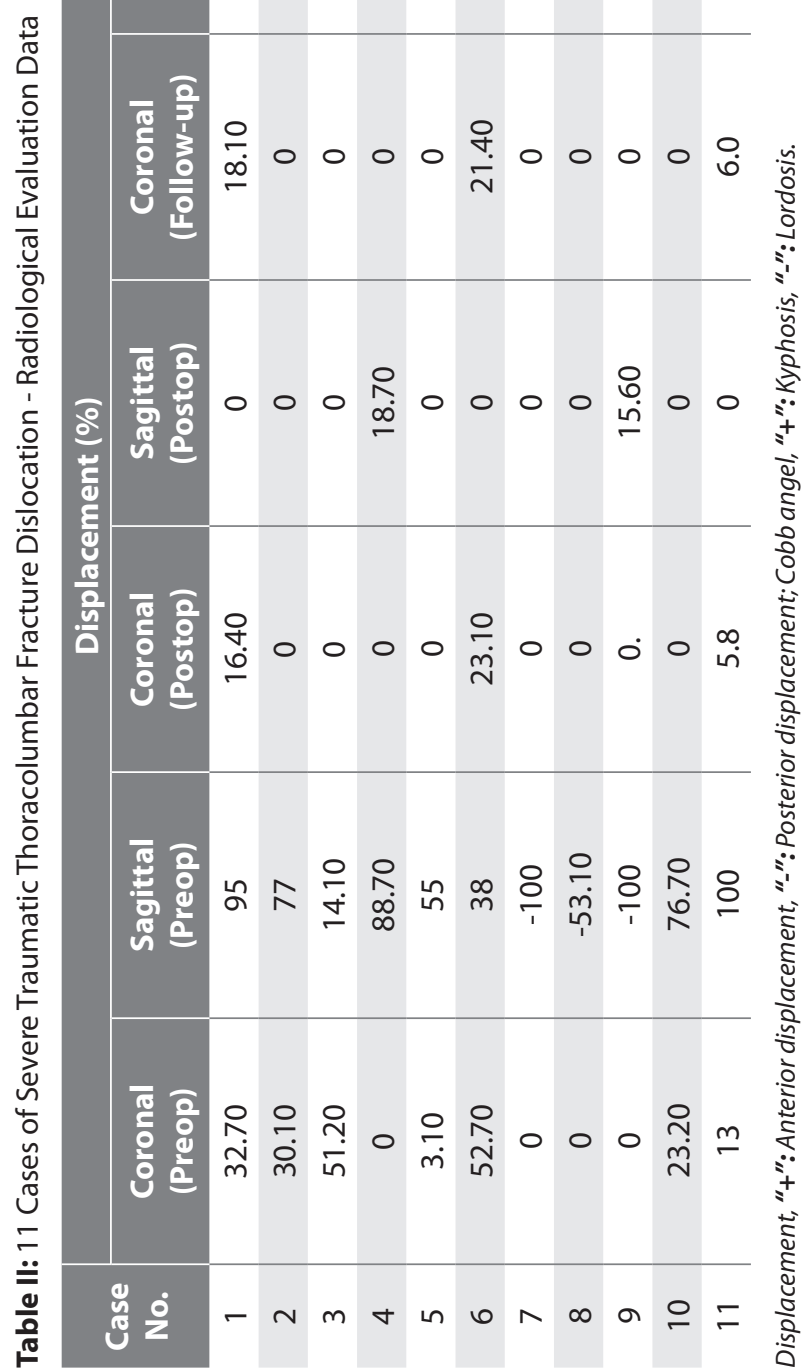


patients were transferred from other hospitals more than 72 h after injury. We observed no surgery-related complication, indicating that early surgery does not increase the risk of mortality and morbidity in severe thoracolumbar fracture/ dislocation.
Given the neurological status in severe thoracolumbar fracture/dislocation, surgical treatment has two roles: affording a stable mechanical environment and restoring CSF flow for potential neurological recovery by correcting the spinal malalignment, decompressing the canal, and gaining long-term stability with instrumentation and spinal fusion.
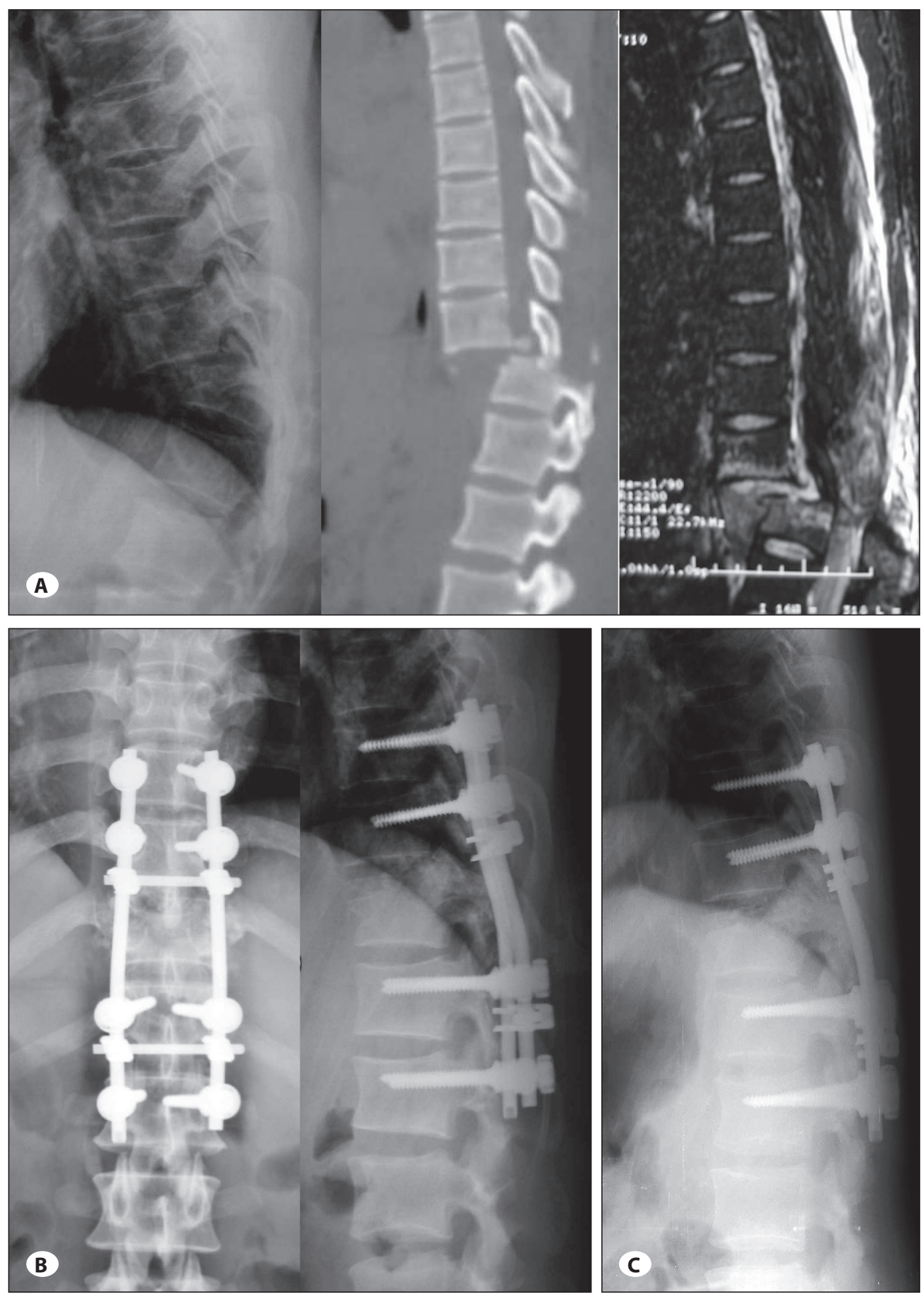

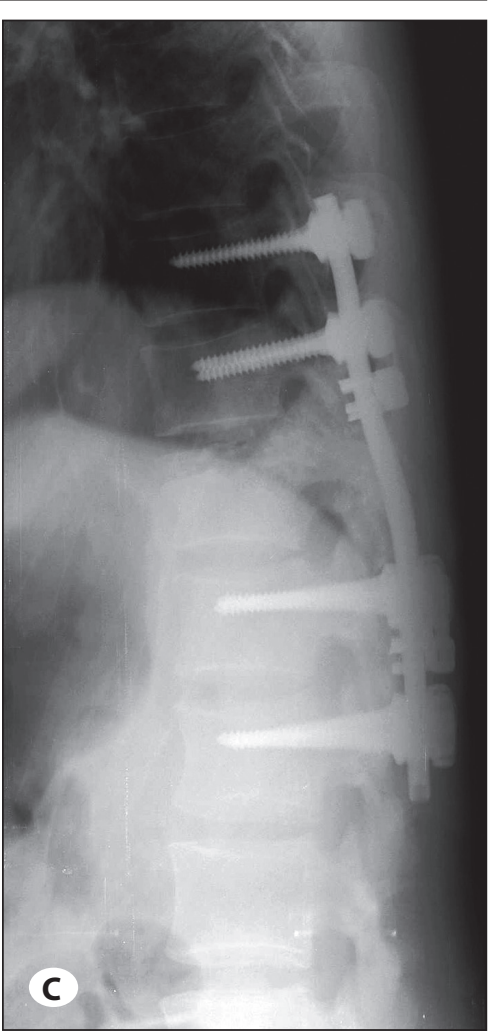

Figure 1: Radiographic data from a 25-year-old man who presented with $\mathrm{T} 11$ fracture and T10-11 dislocation after traffic accident. (A) Preoperative $X$ ray showing the fracture and severe dislocation with 55\% sagittal displacement. Preoperative CT scan and MRI also demonstrating severe fracture-dislocation and spinal cord compression.

(B) Postoperative AP and Lateral $X$ ray showing satisfactory reduction with good segment alignment. (C) The last follow-up $X$ ray showing stable local mechanical reconstruction with no loss of correction and hardware failure after 17 months follow-up. 

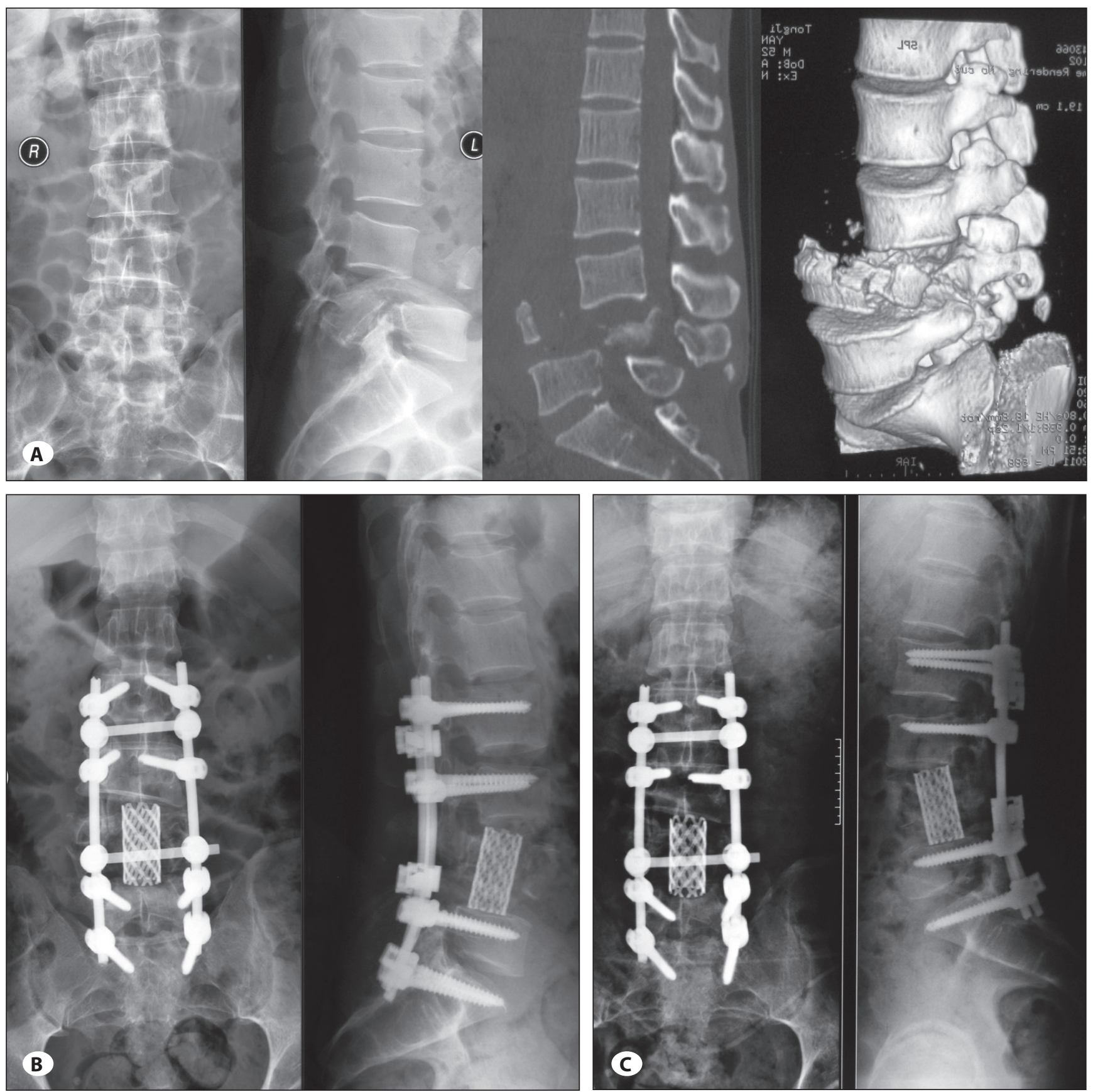

Figure 2: Radiographic data obtained in a 52-year-old man who presented with L4 comminuted fracture and complete L4 posterior spondyloptosis on L5. (A) Preoperative X ray and CT scan showing L4 comminuted fracture and posterior spondyloptosis of L4 on L5. (B) Postoperative AP and Lateral X ray showing satisfactory segment alignment after partial L4 corpectomy, anterior reconstruction with autograft filled mesh cage and posterior instrumentation from $L 2$ to the sacrum. (C) 2 years follow-up X ray showing stable local mechanical reconstruction with no loss of correction and hardware failure.

Thoracolumbar fracture/dislocation produces the worst biomechanical conditions, which place the highest demands on stable reconstruction with internal fixation. Severe spine malalignment in two planes is difficult to restore and maintain via single anterior fixation and fusion. Therefore, the surgical approach of choice includes posterior and combined approaches (37). Traditionally, combined approaches were thought to afford better decompression under direct vision, superior biomechanical stability with anterior column support and reconstruction, and a limited number of mobile segments included in the fusion compared with the posterior approach alone. However, the combined approach has a higher risk of intra- and postoperative complications, more blood loss, longer operating time, and greater costs than the posterior 
approach alone (15,26). Recently, Yadla et al. (42) treated five cases of traumatic thoracolumbar junction spondyloptosis with a combined approach: three cases had complications, including prolonged intubation and postoperative DVT. In a retrospective study, Lu et al. (21) found that the morbidity of the posterior approach was lower than that of an anteriorposterior approach. Moreover, anterior transthoracic approaches are less well tolerated by multiple trauma patients with associated chest trauma. Circumferential decompression and reconstruction via a single posterior approach was initially reported in the treatment of spinal tumors and severe spinal deformities. Because this approach maintains most of the advantages related to the anterior approach while obviating the inherent risks, it is now often used in trauma patients $(3,4,10,18,19,31,35,41)$. Rene et al. (31) reported satisfactory anterior column reconstruction with monocortical strut grafts via a technique similar to posterior lumbar interbody fusion (PLIF)/TLIF in 100 patients with thoracolumbar fractures. Follow-up in 82 patients proved that the load-bearing capacity of the anterior column was restored. Sasani (30) and Yang et al. (10) introduced the three-column reconstruction technique via a posterior approach alone in unstable thoracolumbar fractures, in which the fractured vertebra was resected subtotally and the anterior column restored with a mesh cage. Local mechanical stability was confirmed in all patients after an average 2-year follow-up period. In this series, anterior reconstruction was performed with the TLIF technique in 10 cases that had relatively complete endplates at the fracture/dislocation level or a mild compressed fracture $(<1 / 3$ body height collapse) of the vertebra adjacent to the fracture/dislocation. In one case with significant impairment of the anterior column that presented with a comminuted split fracture and fragment displacement, we chose a partial corpectomy and implanted an autograft-filled mesh cage for anterior column reconstruction. In our experience, anterior reconstruction through a posterior approach was convenient and timesaving, because the spinal canal was decompressed anteriorly as a precondition for a safe reduction. After reduction and temporary fixation, we could rapidly prepare for anterior reconstruction. This is another reason why we prefer the posterior approach alone, rather than a combined approach.

Long-segment posterior constructs serve well in thoracic and thoracolumbar burst fractures biomechanically, whereas short-segment fixation combined with anterior fixation is advocated in unstable lumbar fractures, offering the advantage of maintaining more mobile lumbar segments $(17,23)$. In this series, we normally fixed the affected level at two levels above and below it and mounted two cross-link connectors at the proximal and distal ends. We choose longsegment posterior fixation for two reasons. First, using the loading-share score of McCormack et al. (22), all 11 patients had scores $>7$ and the use of long constructs with anterior support is the optimal choice for adequate stability (1). Second, long constructs afford a long lever arm for reduction, which is especially important in coronal plane realignment.
Multiple anchorages also shared the force, preventing pedicle screw pullout during the reduction maneuver. To achieve anterior reconstruction, titanium mesh was inserted in one case through a posterior approach; the key technical point is to prepare mesh shorter than the original intervertebral space and compress and shorten the space after positioning the mesh. Consequently, the direct contact between the autograft-filled mesh and healthy surface of bleeding bone of the upper and lower vertebra and the surrounding remnants of the fractured vertebra affords biologically favorable conditions for rapid, solid fusion. We obtained stable biomechanical reconstruction in our patients with severe fractures/dislocations with long-segment posterior fixation. In our series, 10 patients presented with ASIA grade A neurological impairment and one patient with ASIA grade B. Three patients improved postoperatively, by less than one grade in sensation or movement. Nevertheless, early surgical decompression, reduction, and stabilization of the extremely unstable fracture/dislocation allow the early initiation of rehabilitation and the establishment of an amicable local environment for preventing secondary spinal cord injury. This is a good basis for future spinal cord regeneration therapy, such as stem cell transplantation.

\section{CONCLUSIONS}

Traumatic thoracolumbar fractures with severe dislocations were treated successfully using a single-stage procedure with circumferential decompression, reduction, anterior column reconstruction, and multisegmental fixation with pedicle screw/rod instrumentation through a posterior approach alone. The absence of the risks related to the anterior approach, fewer complications in our series, maintenance of deformity correction, and stable local mechanical reconstruction observed at the latest follow-up evaluation support this single-approach strategy.

\section{REFERENCES}

1. Altay M, Ozkurt B, Aktekin CN: Short- or long-segment posterior fixation in magerl type a fractures. Eur Spine J 16:1145-1155, 2007

2. Bernstein MP, Mirvis SE, Shanmuganathan K: Chance-type fractures of the thoracolumbar spine: Imaging analysis in 53 patients. AJR Am J Roentgenol 187:859-868, 2006

3. Boachie-Adjei O, Bradford DS: Vertebral column resection and arthrodesis for complex spinal deformities. J Spinal Disord 4:193-202, 1991

4. Bradford DS, Tribus CB: Vertebral column resection for the treatment of rigid coronal decompensation. Spine (Phila Pa 1976) 22:1590-1599, 1997

5. Chipman JG, Deuser WE, Beilman GJ: Early surgery for thoracolumbar spine injuries decreases complications. J Trauma 56:52-57, 2004

6. Denis F: Spinal instability as defined by the three-column spine concept in acute spinal trauma. Clin Orthop Relat Res $65-76,1984$ 
7. Denis $F$ : The three column spine and its significance in the classification of acute thoracolumbar spinal injuries. Spine (Phila Pa 1976) 8:817-831, 1983

8. Fox JT, Huang YC, Barcia PJ: Blunt abdominal aortic transection in a child: Case report. J Trauma 41:1051-1053, 1996

9. Golledge J, Muller R, Clancy P: Evaluation of the diagnostic and prognostic value of plasma D-dimer for abdominal aortic aneurysm. Eur Heart J 32:354-364, 2011

10. Haiyun $Y$, Rui G, Shucai D: Three-column reconstruction through single posterior approach for the treatment of unstable thoracolumbar fracture. Spine (Phila Pa 1976) 35:E295-302, 2010

11. Harris MB, Sethi RK: The initial assessment and management of the multiple-trauma patient with an associated spine injury. Spine (Phila Pa 1976) 31:S9-15; discussion S36, 2006

12. Hauser CJ, Visvikis G, Hinrichs C: Prospective validation of computed tomographic screening of the thoracolumbar spine in trauma. J Trauma 55:228-234; discussion 234-225, 2003

13. Inaba K, Kirkpatrick AW, Finkelstein J: Blunt abdominal aortic trauma in association with thoracolumbar spine fractures. Injury 32:201-207, 2001

14. Keynan O, Fisher CG, Vaccaro A: Radiographic measurement parameters in thoracolumbar fractures: A systematic review and consensus statement of the spine trauma study group. Spine (Phila Pa 1976) 31:E156-165, 2006

15. Knop C, Blauth M, Buhren V: Surgical treatment of injuries of the thoracolumbar transition--3: Follow-up examination. Results of a prospective multi-center study by the "Spinal" Study Group of the German Society of Trauma Surgery. Unfallchirurg 104:583-600, 2001

16. Koracevic GP: Pragmatic classification of the causes of high D-dimer. Am J Emerg Med 27:1016 e 1015-1017, 2009

17. Lazaro BC, Deniz FE, Brasiliense LB: Biomechanics of thoracic short versus long fixation after 3-column injury. J Neurosurg Spine 14:226-234, 2011

18. Lenke LG, O'Leary PT, Bridwell KH: Posterior vertebral column resection for severe pediatric deformity: Minimum two-year follow-up of thirty-five consecutive patients. Spine (Phila Pa 1976) 34:2213-2221, 2009

19. Lenke LG, Sides BA, Koester LA: Vertebral column resection for the treatment of severe spinal deformity. Clin Orthop Relat Res 468:687-699, 2010

20. Lieberman I, Chiasson D, Podichetty VK: Aortic disruption associated with L2-L3 fracture-dislocation in a case of child abuse: A case report. J Bone Joint Surg Am 92:1670-1674, 2010

21. Lu DC, Lau D, Lee JG: The transpedicular approach compared with the anterior approach: An analysis of 80 thoracolumbar corpectomies. J Neurosurg Spine 12:583-591, 2010

22. McCormack T, Karaikovic E, Gaines RW: The load sharing classification of spine fractures. Spine (Phila Pa 1976) 19: 1741-1744, 1994
23. McLain RF: The biomechanics of long versus short fixation for thoracolumbar spine fractures. Spine (Phila Pa 1976) 31: S70-79; discussion S104, 2006

24. McLain RF, Benson DR: Urgent surgical stabilization of spinal fractures in polytrauma patients. Spine (Phila Pa 1976) 24:1646-1654, 1999

25. Meyerding HW: Spondylolisthesis; surgical fusion of lumbosacral portion of spinal column and interarticular facets; use of autogenous bone grafts for relief of disabling backache. J Int Coll Surg 26:566-591, 1956

26. P PO, Tuinebreijer WE, Patka P: Combined anterior-posterior surgery versus posterior surgery for thoracolumbar burst fractures: A systematic review of the literature. Open Orthopaedics Journal 4:93-100, 2010

27. Patel AA, Dailey A, Brodke DS: Thoracolumbar spine trauma classification: The Thoracolumbar Injury Classification and Severity Score System and case examples. J Neurosurg Spine 10:201-206, 2009

28. Ploumis A, Ponnappan RK, Bessey JT: Thromboprophylaxis in spinal trauma surgery: Consensus among spine trauma surgeons. Spine J 9:530-536, 2009

29. Rossi EC, Green D, Rosen JS: Sequential changes in factor VIII and platelets preceding deep vein thrombosis in patients with spinal cord injury. Br J Haematol 45:143-151, 1980

30. Sasani M, Ozer AF: Single-stage posterior corpectomy and expandable cage placement for treatment of thoracic or lumbar burst fractures. Spine (Phila Pa 1976) 34:E33-40, 2009

31. Schmid R, Krappinger D, Seykora P: PLIF in thoracolumbar trauma: Technique and radiological results. Eur Spine J 19:1079-1086, 2010

32. Sekhon LH, Sears W, Lynch JJ: Surgical management of traumatic thoracic spondyloptosis: Review of 2 cases. J Clin Neurosci 14:770-775, 2007

33. Shapiro S, Abel T, Rodgers RB: Traumatic thoracic spinal fracture dislocation with minimal or no cord injury. Report of four cases and review of the literature. J Neurosurg 96: 333-337, 2002

34. Shimony A, Filion KB, Mottillo S: Meta-Analysis of Usefulness of D-Dimer to Diagnose Acute Aortic Dissection. Am J Cardiol, 2011

35. Tomita K, Kawahara N, Murakami H: Total en bloc spondylectomy for spinal tumors: Improvement of the technique and its associated basic background. J Orthop Sci 11:3-12, 2006

36. Vaccaro AR, Lehman RA, Jr, Hurlbert RJ: A new classification of thoracolumbar injuries:The importance of injury morphology, the integrity of the posterior ligamentous complex, and neurologic status. Spine (Phila Pa 1976) 30:2325-2333, 2005

37. Vaccaro AR, Lim MR, Hurlbert RJ: Surgical decision making for unstable thoracolumbar spine injuries: Results of a consensus panel review by the Spine Trauma Study Group. J Spinal Disord Tech 19:1-10, 2006 
38. Verhelst L, Ackerman P, Van Meirhaeghe J: Traumatic posterior lumbosacral spondyloptosis in a six-year-old: A case report and review of the literature. Spine (Phila Pa 1976) 34: E629-634, 2009

39. Vialle R, Rillardon L, Feydy A: Spinal trauma with a complete anterior vertebral body dislocation: A report of three cases. Spinal Cord 46:154-158, 2008

40. Vialle R, Wolff S, Pauthier F:Traumatic lumbosacral dislocation: Four cases and review of literature. Clin Orthop Relat Res 91-97, 2004

41. Wang Y, Lenke LG: Vertebral column decancellation for the management of sharp angular spinal deformity. Eur Spine J 20:1703-1710, 2011
42. Yadla S, Lebude B, Tender GC: Traumatic spondyloptosis of the thoracolumbar spine. J Neurosurg Spine 9:145-151, 2008

43. Yazici M, Alanay A, Aksoy MC: Traumatic L1-L2 dislocation without fracture in a 6-year-old girl. Incomplete neurologic deficit and total recovery. Spine (Phila Pa 1976) 24:1483-1486, 1999

44. Zhang JW, Xiao BP, Xu RM: Analysis of safety and effect of reconstructing anterior and middle columns by single posterior approach in treating lumbar burst fractures. Chin J Traumatol 12:107-112, 2009 